\title{
PowerStaTim 1.0 - un nou program statistic de calcul a mărimii efectului și a puterii statistice
}

\author{
Florin A. Sava ${ }^{1}$ \\ Laurențiu P. Maricuțoiu \\ Universitatea de Vest din Timișoara
}

\begin{abstract}
The present paper presents the main characteristics of a new software for computing effect size and statistical power indicators: PowerStaTim 1.0 (Maricutoiu \& Sava, 2007). The first part of the present paper presents the rationale for computing effect size and statistical power in psychological research. The second part of the article introduces the reader to the technical characteristics of PowerStaTim 1.0 and to the processing options of this software.
\end{abstract}

Key words: statistical power, effect size, sample size, software

\section{Rezumat}

Lucrarea de față prezintă principalele caracteristici ale unui nou program statistic de calcul al indicatorilor mărimii efectului şi puterii statistice: PowerStaTim 1.0 (Maricuțoiu \& Sava, 2007). Prima parte a articolului prezintă argumentele care explica necesitatea calculării mărimii efectului şi a puterii statistice în cercetarea psihologică. A doua parte familiarizează cititorul cu caracteristicile tehnice ale PowerStaTim 1.0 şi cu opțiunile de procesare oferite de acest program statistic.

Cuvinte cheie: puterea statistică, mărimea efectului, dimensiunea eşantionului, program statistic

\section{Introducere}

Probabil fiecare dintre cei care citesc acest text s-a confruntat, în contexte de cercetare, cu o serie de întrebări fireşti de genul „De câți participanți am nevoie în studiu?”; „De ce rezultatele mele sunt nesemnificative statistic, deşi literatura de specialitate susține contrariul?”; „Cât de eficientă din punct de vedere practic este intervenție psihologică studiată?”; „Care tratament este mai bun?", „Ce şanse am să obțin un rezultat semnificativ statistic?" etc.

În acest moment, practica editorilor din reviste de specialitate de a ne pune întrebări legate de mărimea efectului sau de puterea statistică a studiului (APA, 2001) este din ce în ce mai răspândită. Dacă în calitate de autori nu ne-am pus încă asemenea întrebări, cu siguranță o vor face acești editori.

Pentru a răspunde la aceste întrebări va trebui să apelăm la programe specializate de genul G-Power (Faul \& Erdfelder, 1992) sau

\footnotetext{
${ }^{1}$ Adresa de contact: afsava@socio.uvt.ro
}

Power and Precision (Borestein, Rothstein \& Cohen, 2001), care însă prezintă o serie de neajunsuri detaliate în lucrări anterioare (Sava \& Maricutoiu, 2007).

Prin urmare, scopul lucrării de față este de a prezenta succint principalele caracteristici ale PowerStaTim 1.0 (Maricutoiu \& Sava, 2007), ce se constituie într-o alternativă viabilă la programele menționate anterior.

Principalul avantaj al PowerStaTim 1.0 asupra competitorilor este orientarea spre nevoile utilizatorilor şi flexibilitatea input-ului. Astfel, spre deosebire de celelalte software-uri, acest program permite utilizatorilor posibilitatea de a opta pentru una dintre următoarele trei variante: (1) lucrul cu date primare (ex.: outputuri oferite de programe precum SPSS-ul); (2) lucrul cu date secundare complete (ex.: utilizatorul găseşte în articole de specialitate informațiile necesare); (3) lucrul cu date secundare incomplete (ex.: utilizatorul are acces la informații incomplete prezentate în articole de specialitate). 
Alte avantaje care merită reținute sunt: posibilitatea pentru a opta pentru indicatorul mărimii efectului preferat;

- posibilitatea de a consulta o serie de indicatori ajustați, ce permit comparații indiferent de tipul de design al studiului, numărul de variabile implicate etc.;

- cerința de a introduce informații statistice elementare ( $\mathrm{N}$, medii etc.) spre deosebire de alte programe care necesită cunoştințe avansate de metodologie.

Module de calcul ale PowerStaTim 1.0

Din punctul de vedere al procesării, PowerStaTim 1.0 acoperă toate tehnicile statistice parametrice de bază:

- Corelații și regresii liniare;

- Testele t;

- Testele $X^{2}$;

- Testul F (pentru toate formele de ANOVA şi ANCOVA)
Pentru oricare dintre aceste tehnici statistice există un formular pentru calculul $a$ posteriori a mărimii efectului și a puterii statistice (pe baza rezultatelor obținute de utilizator sau găsite în literatura de specialitate), un formular pentru estimarea a priori a numărului de subiecți necesari (pe baza efectului așteptat și a puterii statistice vizate) și un formular de estimare a priori a puterii statistice (pe baza efectului așteptat și a numărului de subiecți disponibili).

\section{Caracteristici de utilizare a PowerStaTim 1.0}

Încă din stadiul de proiectare, PowerStaTim $1.0 \mathrm{~s}$-a dorit a fi un software educațional. Pentru atingerea acestui obiectiv, o atenție specială a fost acordată design-ului aspectelor legate de input-ul și output-ul acestui software, precum și a fișierelor de asistență asociate software-ului (vezi Figura 1).

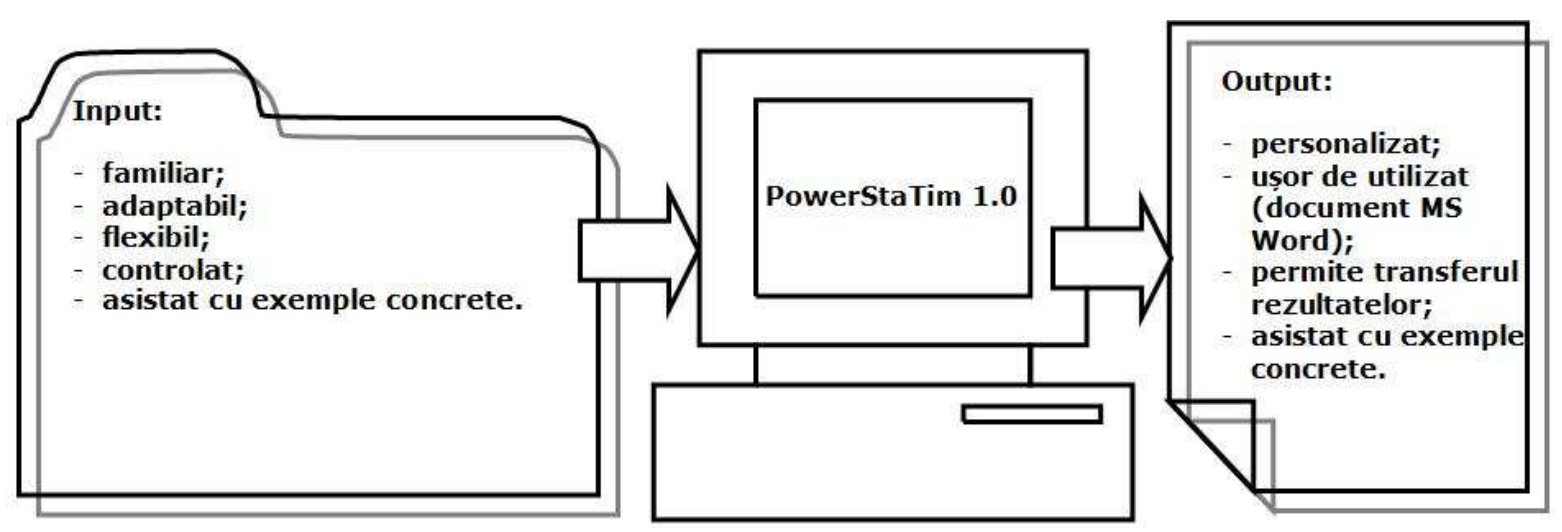

Figura 1. Sumar al caracteristicilor PowerStaTim 1.0

\section{Caracteristici ale input-ului}

Deoarece se adresează unor utilizatori cu cunoștințe minime în ceea ce privește mărimea efectului și puterea statistică, designul input-ului se dorește a fi familiar studenților ce au parcurs un curs de statistică introductivă. Astfel, PowerStaTim 1.0 nu solicită decât informații de bază precum: medii, abateri standard, număr de subiecți, valori ale testelor statistice (t, r, F, beta) și gradele de libertate ale acestor teste (df). Pornind de la aceste valori, PowerStaTim 1.0 calculează automat indici mai puțin familiari precum abaterea standard combinată a mai multor grupe (pooled standard deviation - în engleză) sau media armonică a numărului de subiecți.
Acești indici sunt solicitați de programe similare (Gpower, Power and Precision) deoarece intră în formulele de calcul a indicatorilor de mărimea efectului.

Pentru a ușura introducerea datelor, fiecare fereastră PowerStaTim 1.0 pornește de la informații de bază ale design-ului (numărul de variabile/grupe experimentale/predictori), apoi solicită informații privind numele grupurilor (de exemplu: experimental vs. control), al predictorilor sau al variabilelor dependente. Odată introduse aceste informații, formularul în care trebuie introduse rezultatele obținute se adaptează design-ului definit anterior, oferind utilizatorului indici privind locul specific în care ne așteptăm să introducă anumite informații (vezi Figura 2). 


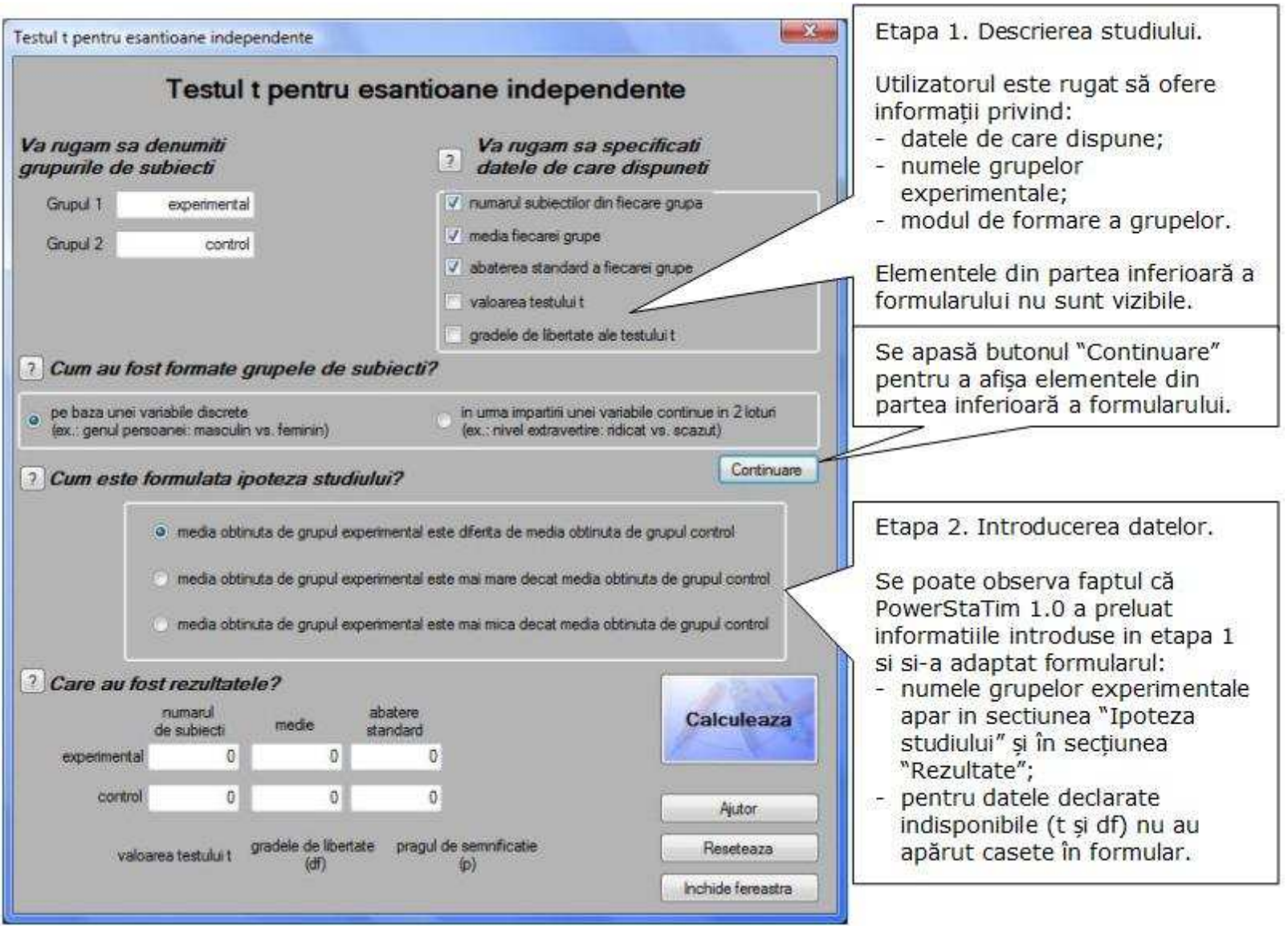

Figura 2. Exemplu de formular din PowerStaTim 1.0

În situația în care utilizatorul are nevoie de asistentă, formularele PowerStaTim 1.0 conțin unul sau mai multe butoane marcate cu simbolul "?", precum și un buton marcat cu textul "Ajutor". Apăsarea acestor butoane deschide o pagină web care conține informații despre:

- $\quad$ tehnica statistică respectivă;

- modul în care se completează formularul din PowerStaTim 1.0;

- modul în care se pot interpreta rezultatele oferite.

Fișierele de asistență sunt sub forma unui website local, care este copiat la instalare. Odată accesat, acest website permite navigarea fără restricții prin toate topicile abordate prin accesarea hyperlink-urilor specifice.

\section{Caracteristici ale output-ului}

În cazul modulelor a posteriori, rezultatele analizei sunt prezentate într-un fișier MS Word. În momentul în care toate calculele sunt realizate, PowerStaTim 1.0 deschide o fereastră de dialog care permite utilizatorului să selecteze locația și (eventual) numele fișierului. Odată salvat, fișierul este deschis automat de PowerStaTim 1.0. Oferirea rezultatelor în acest mod prezintă două mari avantaje, după cum urmează:

- este ușor de utilizat, chiar și pe calculatoare care nu au instalat PowerStaTim 1.0;

- permite transferul rezultatelor în alte documente de tip MS Word: tabelele pot fi transferate ușor, fără riscul unor conflicte de formatare.

De asemenea, rezultatul preia datele introduse în formular și le oferă într-o manieră sintetică. În cazul exemplului din Figura 2, după completarea datelor legate de $N, m$ și $\sigma$, acestea vor fi prezente în fișierul de rezultate alături de rezultatele legate de mărimea efectului și puterea statistică. Mărimea fișierelor poate varia de la 1 pagină până la 3 pagini (în cazul regresiei ierarhice).

În cazul modulelor a priori rezultatele analizei sunt prezentate în cadrul aceleiași ferestre, sub forma unui text. Am optat pentru această variantă deoarece rezultatul poate fi exprimat în cel mult o frază, ceea ce nu ar fi justificat crearea unui fișier MS Word. 


\section{Caracteristici tehnice ale PowerStaTim 1.0.}

PowerStaTim 1.0 a fost programat în Visual Basic.NET 2005, construit pe tehnologia Microsoft .Net Framework 2.0 ß. Din aceste considerente, nu poate fi instalat decât pe sisteme de operare Windows NTß) (Windows 2000, XP, Vista) care au instalată această tehnologie. În plus, pentru funcționarea PowerStaTim 1.0 este nevoie de MS Office XP pentru a putea accesa funcții din MS Excel şi pentru a putea realiza fişierele de raport în MS Word.

Calcularea indicatorilor de mărimea efectului și putere statistică

Deoarece demonstrația este adesea cel mai bun mijloc de exemplificare a utilității unui produs, în final ne vom focaliza asupra unui exemplu relevant pentru utilitatea PowerStaTim.

Două departamente din cadrul aceleiaşi firme desfăşoară o activitate similară, singura diferență fiind tipul de management practicat. În departamentul A s-a adoptat un sistem de salarizare variabil în funcție de performanțele angajaților, în timp ce în departamentul $B$ se practică un sistem de salarizare fix. Un psiholog este interesat să-şi facă disertația pe acest subiect, fiind convins că cel de-al doilea stil produce un nivel mai ridicat de satisfacție printre angajați.

Prin intermediul PowerStaTim 1.0, psihologul ar putea răspunde la o serie de întrebări atât înainte de efectuarea studiului (ex. „De câți angajați am nevoie în studiu?” modulul N a priori din PowerStaTim; „Dacă am acces doar la 40 de angajați ce şanse am să obțin un rezultat semnificativ statistic?" modulul Power a priorı), cât şi după finalizarea studiului (Cât de importantă din punct de vedere practic este diferența observată?" sau "Ce probabilitate există de a fi comis o eroare în testarea ipotezei?" - modulul a posteriorì. În continuare sunt oferite răspunsurile PowerStaTim 1.0 la cele patru întrebări ridicate.

1. De câți angajați este nevoie să fie incluşi ca participanți în studiu?

Din datele problemei rezultă cazului testului t pentru 2 eşantioane independente şi al unei ipoteze unilaterale. Din literatura metodologică ştim că un studiu optim configurat ar trebui să aibă o putere statistică de .80 , iar mărimea efectului de o intensitate cel puțin medie are valoarea de .50 în cazul indicatorului $d$ al lui Cohen. Introducând aceste date în PowerStaTim 1.0, rezultă că am avea nevoie de 50 de participanți din fiecare departament, ceea ce înseamnă 100 de angajați în total.

2. Dacă am acces doar la 40 de angajați, în total, ce şanse am să obțin un rezultat semnificativ statistic?

Răspunsul la această întrebare este dependent de tipul de efect căutat. De pildă, pentru un efect de intensitate medie precum d $=.50$ şi păstrând aceleaşi condiții prezentate anterior, cu excepția numărului de participanți, vom observa o putere statistică a studiului de .46 dacă cei 40 de angajați sunt împărțiți în două grupe egale. $\mathrm{O}$ asemenea valoare indică faptul că sunt ceva mai puțin de 1 la 1 şanse (.46 / .54) de a obține un rezultat semnificativ statistic chiar dacă ar exista o diferență de intensitate medie între cele două departamente cu privire la satisfacția în muncă.

După finalizarea studiului, prin PowerStaTim se poate răspunde la alte întrebări. Să presupunem că au fost implicați în studiu 60 de angajați, 27 din departamentul A şi 33 din departamentul B, iar indicatorii descriptivi privind satisfacția au fost $(\mathrm{mA}=$ 12.23, $\mathrm{s} A=4,28$, respectiv $\mathrm{mB}=14,56$ şi $\mathrm{sB}=$ $4,71)$.

3. În aceste condiții, diferența sesizată este importantă din punct de vedere practic?

PowerStaTim oferă 0 serie de indicatori ai mărimii efectului ce pot $\mathrm{fi}$ interpretați în variate forme. De pildă, valoarea lui $d$ Cohen este .52, ceea ce indică un efect vizibil, de intensitate medie în plan practic (Cohen, 1988), ce nu poate fi neglijat. O asemenea valoare, transpusă în termeni de percentile, indică faptul că persoanele cu un nivel mediu de satisfacție din departamentul B au un nivel al satisfacției similar cu cele din departamentul $A$ aflate în percentilul 70 , ceea ce indică faptul că majoritatea persoanelor din A (70 de persoane dintr-o 100) au un nivel de satisfacție sub nivelul mediu resimțit în departamentul B.

O altă interpretare posibilă prin apelul la PowerStaTim este oferită prin intermediul $r$ BESD. Astfel, utilizarea unui sistem de salarizare fix față de unul flexibil, induce o creştere a ratei de succes cu privire la satisfacția resimțită în muncă de la $37 \%$ la $63 \%$. În sfârşit, o altă interpretare clasică, bazată pe procentul de dispersie explicată, este posibilă prin intermediul PowerStaTim 1.0. Astfel, deoarece $\mathrm{r}^{2}=.0636$, rezultă că aproximativ $6,36 \%$ din modul în care a variat 
satisfacția angajaților din cele două departamente poate $\mathrm{fi}$ asociat diferențelor existente în sistemul de salarizare.

4. Ce probabilitate există de a fi comis o eroare în testarea ipotezei?

Pornind de la rezultatele descriptive prezentate mai sus, PowerStaTim 1.0 oferă, o dată $\mathrm{cu}$ indicatorii de mărime a efectului, valoarea a posteriori a puterii statistice a studiului efectuat. În cazul dat, puterea statistică, la un prag de .05 este .65 , o valoare considerată satisfăcătoare, dar încă sub nivelul optim standard de .80 (Cohen, 1988). Din perspectiva întrebării puse rezultă că există 0 probabilitate de $.35(1-.65)$ de a comite o eroare de tip II, care transpusă în termeni simpli ar fi cazul în care am concluziona greşit că nu există diferențe semnificative statistic între cele două departamente. În termeni de şansă, acest lucru indică că avem 2 din 3 şanse $(.65 / .35)$ de a trage concluzii corecte şi 1 din 3 şanse de a comite o eroare de tip II.

Cititorii interesați de aceste aspecte pot găsi mai multe detalii în manualul de utilizare a programului (Sava \& Maricuțoiu,
2007), cât şi în fişierele de asistență ce pot fi instalate 0 dată cu PowerStaTim 1.0. Nu ne rămâne decât să vă invităm să le citiți!

\section{Bibliografie}

APA (2001). Publication manual of the American Psychological Association (5th ed.). Washington, DC: American Psychological Association.

Borenstein, M., Rothstein, H., \& Cohen, J. (2001). Power and Precision. Disponibil la: www.poweranalysis.com.

Cohen, J. (1988). Statistical power analysis for the behavioral sciences (2nd ed.). Hillsdale: Erlbaum.

Faul, F., \& Erdfelder, E. (1992). GPOWER: A priori, post hoc, and compromise power analyses for MS-DOS [Computer program]. Bonn University, Dept. of Psychology, Bonn.

Maricuțoiu, L.P, Sava, F.A. (2007). PowerStaTim 1.0 - Analiza puterii statistice şi a mărimii efectului. Disponibil la: www.psihologietm.ro începând cu data de 1.07.2008.

Sava, F.A, \& Maricuțoiu, L.P. (2007). PowerStaTim 1.0. - Manualul utilizatorului. Timişoara: Editura Universității de Vest.

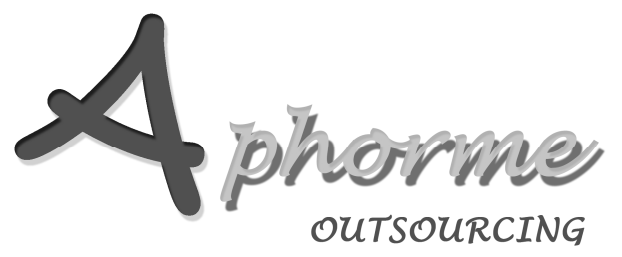

Organizational Diagnosis \& Development

Brand Research

Academic \& Institutional Evaluation

Organizational Simulation \& Gaming

Focus on people and opportunities.

For reliable outcomes

contact@aphorme.ro; www.aphorme.ro 